\title{
Commission 50: Protection of Existing and Potential Observatory Sites
}

\author{
PRESIDENT: Malcolm G. Smith \\ VICE-PRESIDENT: Michelle Storey \\ ORGANIZING COMMITTEE: Jim Cohen, Carlo Blanco, \\ Dave Crawford, Syuzo Isobe, Margarita Metaxa, \\ and Woody Sullivan
}

\begin{abstract}
Significant and specific progress has been made in protecting major astronomical sites during the last three years. A brief summary is given, along with references to some of the efforts by members of Commission 50 to control light pollution and radio-frequency interference.
\end{abstract}

Keywords. RFI, Light pollution, ground-based sites.

\section{Introduction}

The Commission's efforts continue in the following major areas:

- monitoring the conditions at astronomical observing sites, especially those being considered or used for major new telescopes;

- controlling unwanted emissions (light pollution, radio-frequency interference, etc): political action to set appropriate technical standards and regulations;

- education and outreach.

This report covers the primary results of the activities of Commission 50 in the triennium 1st July 2002 to 30th June 2005.

Commission 50 declared Mauna Kea in the Northern hemisphere and Northern Chile in the Southern hemisphere as the top priorities for its site protection program during the period 2002-2005. This was based on the observed scale of astronomical investment already made or committed in these two areas - each at an equivalent rate of over US $\$ 1,000 \mathrm{M}$ per decade. This scale of investment has made it possible for the Commission's members to have influence with authorities who are now taking many of the necessary steps to control the spread of RFI and light pollution.

\section{Controlling Light Pollution}

The Commission works closely with international organizations, maintaining worldwide links with the lighting engineering community though the International Lighting Commission (Commission International d'Eclairage, CIE - http://www.cie.co.at/cie) and through the International Dark-Sky Association (http://www.darksky.org). The Commission's own work in this area continues to be focused through its Working Group on Controlling Light Pollution under its new chairperson, Hugo Schwarz - see his report in another part of this volume. A short illustrated summary of the world-wide status of the efforts to limit light pollution was given in the June 2005 issue of Physics Today Feder (2005). 


\section{RFI Protection}

As in previous years, most international work on controlling radio-frequency interference is carried out internationally through the various bodies associated with the International Telecommunications Union (ITU). These bodies were enumerated and their nature explained in more detail in the introduction to our Commission's report three years ago. At a more local level, a major advance in RFI protection has come with the declaration of the zone around the ALMA site in Chile's northern 2nd Region as a radio-quiet Protection Zone - only the second area in the world to meet the stringent requirements associated with such protection.

\subsection{The ALMA Protection Zone}

On 17th August, 2004 the Chilean telecommunications authorities published Exempt Resolution 1055 establishing a Protection zone and a Coordination Zone on national territory around the ALMA site on the high-altitude Chajnantor plateau above San Pedro de Atacama. Included in the text are the following paragraphs:

4.2. For the purpose of protecting the radio telescope's reception, the following zones have been defined:

a) Protection Zone centered on $23^{\circ} 01^{\prime} \mathrm{S}$ by $67^{\circ} 45^{\prime} \mathrm{W}$ and with a radius of $30 \mathrm{~km}$ within national territory, inside which the installation of any other radio communications system will not be authorized to any third parties operating on the receiving frequency bands mentioned in point 4.1 .

b) Coordination Zone; coordination being understood as the process whereby the opinion of the petitioners, ESO and AUI will be sought regarding certain requests by third parties that this Sub-secretariat deems could interfere or affect the operation of the radio telescope. Likewise, in case such petitioners detect any emissions that affect the operation of the radio telescope, they will notify this Sub-secretariat for its coordination. The deadlines involved for each coordination process will depend on each case. The coordination zone will be centered at $23^{\circ} 01^{\prime} \mathrm{S}$ by $67^{\circ} 45^{\prime} \mathrm{W}$ with a radius of $120 \mathrm{~km}$ inside national territory. Within this zone, any emissions by other petitioners or licensees will be limited...

\section{Acknowledgements}

We would like particularly to acknowledge the support of the International Dark Sky Association (IDA), the Spanish Oficina Tecnica para la Proteccion de la Calidad del Cielo (OTPC) and the Chilean Oficina Para la Proteccion de la Calidad del Cielo del Norte de Chile (OPCC) for their strong astronomical focus in protecting the night-time environment against light pollution.

Our Commission recognizes that professional astronomers (especially members of the IAU) need to get much more involved in this effort. We cannot run away from the problem any longer.

\section{References}

Feder, T 2005, Physics Today June 2005, 25 